\title{
Protein Alterations in Infiltrating Ductal Carcinomas of the Breast as Detected by Nonequilibrium pH Gradient Electrophoresis and Mass Spectrometry
}

\author{
Maria Kabbage, ${ }^{1}$ Karim Chahed, ${ }^{1,2}$ Bechr Hamrita, ${ }^{1}$ Christelle Lemaitre Guillier, ${ }^{3}$ Mounir Trimeche, ${ }^{4}$ \\ Sami Remadi, ${ }^{5}$ Johan Hoebeke, ${ }^{6}$ and Lotfi Chouchane ${ }^{7}$ \\ ${ }^{1}$ Laboratoire d'Immuno-Oncologie Moléculaire, Faculté de Médecine de Monastir, 5019 Monastir, Tunisia \\ ${ }^{2}$ Institut Supérieur de Biotechnologie de Monastir, 5000 Monastir, Tunisia \\ ${ }^{3}$ Plate Forme Protéomique, Institut de Biologie Moléculaire et Cellulaire, CNRS, 67084 Strasbourg, France \\ ${ }^{4}$ Departement de Pathologie, Centre Hospitalo-Universitaire Farhat-Hached, 4002 Sousse, Tunisia \\ ${ }^{5}$ Laboratoire Cytopath, 4000 Sousse, Tunisia \\ ${ }^{6}$ Immunologie et Chimie thérapeutiques, UPR 9021-CNRS, Institut de Biologie Moléculaire et Cellulaire, \\ 67084 Strasbourg, France \\ ${ }^{7}$ Department of Genetic Medicine, Weill Cornell Medical College in Qatar, and Qatar Foundation, Doha, Qatar
}

Correspondence should be addressed to Lotfi Chouchane, loc2008@qatar-med.cornell.edu

Received 8 April 2007; Revised 20 November 2007; Accepted 19 January 2008

Recommended by Halima Bensmail

Improvement of breast-cancer detection through the identification of potential cancer biomarkers is considered as a promising strategy for effective assessment of the disease. The current study has used nonequilibrium $\mathrm{pH}$ gradient electrophoresis with subsequent analysis by mass spectrometry to identify protein alterations in invasive ductal carcinomas of the breast from Tunisian women. We have identified multiple protein alterations in tumor tissues that were picked, processed, and unambiguously assigned identities by matrix-assisted laser desorption/ionization-time of flight mass spectrometry (MALDI-TOF). The proteins identified span a wide range of functions and are believed to have potential clinical applications as cancer biomarkers. They include glycolytic enzymes, molecular chaperones, cytoskeletal-related proteins, antioxydant enzymes, and immunologic related proteins. Among these proteins, enolase 1, phosphoglycerate kinase 1, deoxyhemoglobin, Mn-superoxyde dismutase, $\alpha$-B-crystallin, HSP27, Raf kinase inhibitor protein, heterogeneous nuclear ribonucleoprotein A2/B1, cofilin 1, and peptidylprolyl isomerase A were overexpressed in tumors compared with normal tissues. In contrast, the IGHG1 protein, the complement C3 component C3c, which are two newly identified protein markers, were downregulated in IDCA tissues.

Copyright (c) 2008 Maria Kabbage et al. This is an open access article distributed under the Creative Commons Attribution License, which permits unrestricted use, distribution, and reproduction in any medium, provided the original work is properly cited.

\section{INTRODUCTION}

Breast cancer remains one of the leading causes of death among women worldwide. The incidence rate of this malignancy is steadily rising in developing countries. It is expected to account for $31 \%$ of all new cancer cases among women in USA [1]. In Tunisia, the incidence of breast cancer is approximately 19 new cases per 100000 women per year [2].

Invasive carcinomas where the basement membrane is totally or partially destroyed represent $70-80 \%$ of all breast cancer and include more than 10 different types. Among these, infiltrating ductal carcinomas (IDCA) are the most aggressive forms and have a poor prognosis [3].
Nowadays, improvement of breast-cancer detection at its early stage through the identification of selective diagnostic biomarkers and targets for therapeutic intervention is of critical importance. Alterations that occur in disease versus normal tissues at either the gene or protein level have been regarded as an appropriate way to identify such markers of pathologies. In biomedicine, proteomics, with the recent advances in mass spectrometry, is considered as a powerful analytical method for deciphering protein expression alterations as a function of disease progression [4]. Recently, proteomics-based analyses of breast tissue lysates have resulted in the finding of a number of potential tumor biomarkers providing, therefore, a basis for a 
better understanding of the intracellular signalling pathways leading to breast-cancer development and progression [3], and eventually serving as diagnostic and prognostic markers [5]. Probably the most widely used proteomic technology is the identification of alterations in protein expression between two different samples through comparative two-dimensional gel electrophoresis (2-DE) which provides high-resolution separation of proteins and offers a powerful method for their identification and characterization. Actually, there is no universal 2-DE method that can be applied for all types of samples investigated, and protocols must be optimized and adapted according to the types of tissues and proteins of interest. It is also crucial to minimize protein alterations and degradations that could result in artifactual spots and to improve solubilization procedures in order to avoid loss of proteins during extraction [6].

Although 2-DE is a laborious method, it is still considered as the principal tool in proteomics since it is able to separate proteins according to two independent physicochemical parameters which are isoelectric point and size, and also it provides the highest resolution in the separation of complex protein mixtures [6].2-DE remains however, poor resolutive in detecting proteins that are smaller than $10.000 \mathrm{Da}$ or are basic in charge [7]. An alternative method for the analysis of basic proteins is found in the application of nonequilibrium $\mathrm{pH}$ gradient electrophoresis (NEPHGE), which can provide excellent resolution of basic proteins, offering thus a promising approach for the discovery of tumor-related alterations [8].

In a previous study, we have shown using IEF and mass spectrometry that the levels of a number of proteins including fibrinogen-E, which is a potent antiangiogenic factor, were dysregulated in IDCAs of the breast [9]. In the current report, protein expression profiles issued from breast IDCAs and their matched surrounding histologically normal tissues were examined by NEPHGE two-dimensional gel electrophoresis and MALDI-TOF mass spectrometry. Using this procedure, we established a NEPHGE-2-DE map of proteins altered in IDCAs of the breast. By comparing 2-DE protein profiles, we report herein the identification of several proteins of interest dysregulated in tumor tissues. These altered proteins belong to multiple cellular pathways and may have a pathological role in breast carcinogenesis.

\section{MATERIALS AND METHODS}

\subsection{Sample processing}

Breast tumor samples $(n=10)$ were selected from patients living in the middle coast of Tunisia (median age at diagnosis of 50 years) and classified as infiltrating ductal carcinomas. Breast tumors were obtained with informed consent according to protocols approved by the institutional review boards of the respective hospitals. Carcinomas were pathologically staged according to the TNM (Tumors, Nodes, Metastasis) classification system of UICC [10]. Histological grade was assessed according to the modified SBR grading system [11]. All the tumors investigated were classified as T2/N0 and the grade of the tumors was G3. Breast tumors and surrounding histologically normal tissues were collected at the time of surgery and analyzed by histopathology. Areas of tumor were chosen after assessment by cryostat sectioning. The first, middle, and last sections were stained with hematoxylin and eosin, and examined by a pathologist to ensure that at least $70 \%$ of the tissue sections used for the proteomic study contained tumor cells. The nontumor tissues were confirmed by cryostat section before protein extraction. For proteomic analyses, tissue sections verified histologically were suspended and homogenized in $250 \mu \mathrm{L}$ of $2-\mathrm{DE}$ analysis buffer: $7 \mathrm{M}$ urea, $2 \mathrm{M}$ thiourea, $4 \%$ CHAPS, 0.5\% DTT, and $2 \%$ ampholytes ( 1 part $\mathrm{pH} 3 / 10,1$ part $\mathrm{pH} 5 / 7,2$ parts $\mathrm{pH} 6 / 8$ ). The clear supernatant issued after centrifugation of the homogenate at $12500 \mathrm{~g}$ for 15 minutes was transferred to a sterile microcentrifuge tube and immediately subjected to 2-DE analysis.

\subsection{Nonequilibrium $\mathrm{pH}$ gradient electrophoresis, Isoelectrofocalization and SDS-PAGE}

Protein contents were determined according to the procedure described by Bradford and modified by Ramagli and Rodriguez [12]. Bovine serum albumin (Fraction V, Sigma) was used as a standard. Analytical 2-DE was carried out in a BioRad system (Miniprotean II). Equal amounts of proteins $(100 \mu \mathrm{g})$ issued from tumor or nontumor breast tissues were applied to the first dimension and at least three NEPHGE gels were run for each sample. NEPHGEhas been used to resolve basic proteins as described earlier [8]. IEF was performed as described previously [9]. For each experiment, extraction of proteins, solubilization, NEPHGE, and SDS-PAGE were carried under similar conditions for the tumor and nontumor tissues. Electrophoresis was performed in triplicate for each pair of samples to ensure reproducibility. The alterations reported in the current study were retained after 2-DE analysis of protein extracts issued respectively from different frozen sections of the 10 tumor and nontumor samples investigated. The reproducibility was about $85 \%$ or more which reflected the small variances between samples or running.

\subsection{Gel staining}

After separation, the proteins were visualized by a sensitive colloidal Coomassie G250 stain [13]. The dye solution contained $17 \%(\mathrm{w} / \mathrm{v})$ ammonium sulfate, $3 \%(\mathrm{v} / \mathrm{v})$ phosphoric acid, 0,1\% (w/v) Coomassie G250, and 34\% (v/v) methanol. The staining solution was changed once after 12 hours staining and the gel slabs subjected to a 24-hour cycle for increasing dye deposition on low-abundance proteins. The detection was then increased by placing the gel into $1 \% \mathrm{v} / \mathrm{v}$ acetic acid for producing a better contrast between spots and gel. Coomassie stained gels were scanned and spot detection and quantification were carried out using PDQuest 2-D software version 7.2 (Biorad). Proteins with significant and reproducible changes between tumor and nontumor tissues were considered as differentially expressed. The abundance of each protein was estimated by the percentage volume. The individual spot volumes were normalized by dividing their 
optical density (OD) volumes by the total OD values of all the spots present in the gel and expressed as \% vol. The significance of expression between tumor and nontumor tissues was estimated by student's $t$-test, $P<.05$.

\subsection{Spot picking and in-gel digestion}

Picked spots were washed with $100 \mu \mathrm{L}$ of $25 \mathrm{mM} \mathrm{NH}_{4} \mathrm{HCO}_{3}$ and dehydrated with $100 \mu \mathrm{L}$ of acetonitrile (ACN). This operation was repeated twice and the pieces of gel were dried under vacuum for 10 minutes. Reduction was achieved by 1-hour treatment with $10 \mathrm{mM} \mathrm{DTT}$ in $\mathrm{NH}_{4} \mathrm{HCO}_{3}$ buffer $(100 \mu \mathrm{L})$ at $56^{\circ} \mathrm{C}$. After discarding the DTT solution, alkylation reaction was performed by the addition of $100 \mu \mathrm{L}$ of $25 \mathrm{mM}$ iodoacetamide in $25 \mathrm{mM} \mathrm{NH}_{4} \mathrm{HCO}_{3}$ buffer for 1 hour at room temperature, protected from light. Finally, the excised gel pieces were again washed 3 times for 5 minutes with $25 \mathrm{mM} \mathrm{NH}_{4} \mathrm{HCO}_{3}$ and $\mathrm{ACN}$ alternately. Gel pieces were completely dried under vacuum before tryptic digestion. The dried gel volume was evaluated (about 1 to $2 \mu \mathrm{L}$ ) and 3 volumes of trypsin (Promega, V5111), $12.5 \mathrm{ng} / \mu \mathrm{L}$, in $25 \mathrm{mM}$ $\mathrm{NH}_{4} \mathrm{HCO}_{3}$ buffer (freshly diluted), were added. The digestion was performed at room temperature overnight. Afterwards, $5 \mu \mathrm{L}$ of $35 \% \mathrm{H}_{2} \mathrm{O} / 60 \% \mathrm{ACN} / 5 \% \mathrm{HCOOH}$ were added and the mixture is sonicated for 30 minutes and centrifuged in order to extract tryptic peptides.

\subsection{Protein identification by MALDI-TOF-MS}

Mass measurements were carried out on a BIFLEX III MALDI-TOF (Bruker, Daltonics, Bremen, Ge) equipped with the SCOUT high-resolution optics with X-Y multisample probe and gridless reflector. This instrument was used at a maximum accelerating potential of $19 \mathrm{kV}$ (in positive mode) and was operated in reflector mode. A saturated solution of $\alpha$-cyano-4-hydroxycinnamic acid (Sigma, Saint Louis, MO) in acetone was used as a matrix. A first layer of fine matrix crystals was obtained by the spreading and fast evaporation of $0.5 \mu \mathrm{L}$ of matrix solution. On this fine layer of crystals, a droplet of $0.5 \mu \mathrm{L}$ of aqueous $\mathrm{HCOOH}(5 \%)$ solution was deposited. Afterwards, $0.5 \mu \mathrm{L}$ tryptic digest were added and mixed to a second dried under vacuum. The sample was washed once by applying $0.7 \mu \mathrm{L}$ of aqueous $\mathrm{HCOOH}(5 \%)$ solution on the target and then flushed after a few seconds. In positive mode, internal calibration was performed with tryptic peptides coming from autodigestion of trypsin, with respectively monoisotopic masses at $\mathrm{m} / \mathrm{z}=842.510$ and $\mathrm{m} / \mathrm{z}$ $=2211.105$. Monoisotopic peptide masses were assigned and used for databases searches. For the mass measurements, up to 1 missed tryptic cleavage and optional methionine oxidation were considered. In most cases, the mass accuracy was less than $50 \mathrm{ppm}$, a value which is generally considered adequate for achieving statistically significant results for protein identification. These files were then fed into the search engine MASCOT (Matrix Science, London, UK). The data were searched against NCBI nonredundant protein sequence database.

\subsection{Immunohistochemistry (IHC)}

IHC analysis of $\alpha$-B crystallin was performed on formalinfixed, paraffin-embedded sections of IDCA breast tumors. Standard indirect immunoperoxidase procedures were used for detection of $\alpha$-B crystallin. Briefly, five-micrometer sections were deparaffinized in toluene and subsequently hydrated with graded ethanol, and rehydrated in water. Slides were microwaved in $0.01 \mathrm{M}$ citrate buffer at $\mathrm{pH} 6.0$ for 20 minutes at $750 \mathrm{~W}$. Thereafter, sections were rinsed thoroughly with water and placed in a Tris-buffered saline (TBS) solution (0.05 M Tris- $\mathrm{HCl} \mathrm{pH} 7.6,1.15 \mathrm{M} \mathrm{NaCl})$. Endogenous peroxidase activity was blocked with hydrogen peroxide solution for 7 minutes and sections were rinsed gently with TBS. Sections were then incubated at $4^{\circ} \mathrm{C}$ overnight with the antibody against $\alpha$-B crystallin (AB1546, Chemicon) at a dilution of $1: 1000$. After rinsing in TBS, sections were incubated with the secondary antibody, DakoCytomation EnVision+Dual Link System Peroxydase (DakoCytomation, Glostrup, Denmark), for 30 minutes. Sections were washed 2 times with TBS, followed by application of the diaminobenzidine substrate pack according to the manufacturer's instructions (DakoCytomation), yielding a browncolored signal. Finally, tissue sections were counterstained with hematoxylin and mounted. Standardization of the incubation and development times allowed an accurate comparison of expression levels in all cases. IHC staining was evaluated by two independent pathologists for staining intensity. Cases were considered positive if $10 \%$ or more of the tumor cells showed unequivocal immunoreactivity.

\section{RESULTS}

In the current study, we have used an NEPHGE-2-DE protocol for the analyses of basic proteins, and using this procedure established an NEPHGE-2-DE map of proteins altered in IDCAs of the breast. Since NEPHGE is stopped before equilibrium is attained, accurate experimental estimation of the pIs of the dysregulated proteins cannot be made by this method. Table 1 depicts the theoretical isoelectric points (pIs) and molecular weights of altered proteins in tumor tissues, many of which are basic. In our hands, while NEPHGE2-DE allowed the resolution of basic proteins, IEF-2-DE resulted as expected in the stacking of most of basic proteins at the basic end, even if the IEF pH gradient has been extended to higher $\mathrm{pH}$ values.

In our hands, a comparison of the 2-DE protein patterns obtained at constant voltages of $400 \mathrm{~V}$ for 3 hours (1200 V$\mathrm{Hr})$ or 4 hours $(1600 \mathrm{~V}-\mathrm{Hr})$ showed an optimal resolution of basic proteins at $1200 \mathrm{~V}-\mathrm{Hr}$ while preventing basic proteins from running off the basic end of the gels. By using the protein extraction procedure listed in Section 2, an average amount of $100 \mu \mathrm{g}$ of total proteins from each sample was used in 2-DE investigations. Figure 1 displays electrophoresis patterns of proteins from tumor and nontumor samples subjected to NEPHGE-2-DE electrophoresis. By using this procedure, we have found that the majority of the proteins displayed were not different in abundance between normal and cancer tissues. Protein alterations occurring in 
TABLE 1: Results of MALDI-TOF mass spectra and database searching for protein identification.

\begin{tabular}{|c|c|c|c|c|c|c|c|c|c|}
\hline \multirow{2}{*}{$\begin{array}{l}\text { Identified } \\
\text { proteins }\end{array}$} & \multirow{2}{*}{$\begin{array}{l}\text { Spot }^{(a)} \\
\text { number }\end{array}$} & \multirow{2}{*}{$\begin{array}{l}\operatorname{Mr}(\mathrm{kDa}) / \\
\mathrm{pI}^{(\mathrm{b})}\end{array}$} & \multirow{2}{*}{$\begin{array}{l}\text { Access } \\
\mathrm{N}^{\circ(\mathrm{c})}\end{array}$} & \multirow{2}{*}{$\begin{array}{l}\text { Peptides } \\
\text { matched }\end{array}$} & \multicolumn{2}{|c|}{ Relative $^{(\mathrm{d})}$ volume (\%) } & \multirow{2}{*}{$\begin{array}{l}\text { Mass } \\
\text { accuracy } \\
(\mathrm{ppm})\end{array}$} & \multirow{2}{*}{$\begin{array}{l}\text { Sequence } \\
\text { coverage } \%\end{array}$} & \multirow{2}{*}{$\begin{array}{l}\text { Reported } \\
\text { function }\end{array}$} \\
\hline & & & & & $\mathrm{N}$ & $\mathrm{T}$ & & & \\
\hline $\begin{array}{l}\text { Complement } \\
\text { component C3c } \\
\text { (chainD) }\end{array}$ & 1 & $71317 / 6.82$ & 78101272 & 36 & $0.085 \pm 0.015$ & $0.02 \pm 0.007$ & 45 & 64 & $\begin{array}{l}\text { Immune } \\
\text { response }\end{array}$ \\
\hline IGHG1 protein & 2 & $45286 / 8.63$ & 44890623 & 9 & $0.121 \pm 0.001$ & $0.021 \pm 0.008$ & 42 & 27 & $\begin{array}{l}\text { Immune } \\
\text { response }\end{array}$ \\
\hline IGHG1 protein & 3 & $45286 / 8.63$ & 44890623 & 9 & $0.142 \pm 0.008$ & $0.041 \pm 0.006$ & 43 & 29 & $\begin{array}{l}\text { Immune } \\
\text { response }\end{array}$ \\
\hline IGHG1 protein & 4 & $45286 / 8.63$ & 44890623 & 7 & $0.12 \pm 0.004$ & $0.019 \pm 0.009$ & 50 & 24 & $\begin{array}{l}\text { Immune } \\
\text { response }\end{array}$ \\
\hline IGHG1 protein & 5 & $45286 / 8.63$ & 44890623 & 7 & $0.101 \pm 0.006$ & $0.014 \pm 0.005$ & 50 & 24 & $\begin{array}{l}\text { Immune } \\
\text { response }\end{array}$ \\
\hline IGHG1 protein & 6 & $45286 / 8.63$ & 44890623 & 7 & $0.095 \pm 0.007$ & $0.017 \pm 0.006$ & 50 & 24 & $\begin{array}{l}\text { Immune } \\
\text { response }\end{array}$ \\
\hline $\begin{array}{l}\text { Carbonic } \\
\text { anhydrase } 1\end{array}$ & 7 & $28909 / 6.59$ & 4502517 & 13 & $0.081 \pm 0.01$ & $0.018 \pm 0.009$ & 72 & 72 & $\begin{array}{l}\text { metabolic } \\
\text { enzyme }\end{array}$ \\
\hline Enolase1 & 8 & $47481 / 7.01$ & 4503571 & 30 & $0.012 \pm 0.001$ & $0.131 \pm 0.006$ & 41 & 62 & $\begin{array}{l}\text { Glycolytic } \\
\text { enzyme }\end{array}$ \\
\hline $\begin{array}{l}\text { phosphoglycerate } \\
\text { kinase } 1\end{array}$ & 9 & $44973 / 8.30$ & 48145549 & 28 & $0.015 \pm 0.007$ & $0.108 \pm 0.03$ & 60 & 58 & $\begin{array}{l}\text { Glycolytic } \\
\text { enzyme }\end{array}$ \\
\hline $\begin{array}{l}\text { Deoxy } \\
\text { hemoglobin } \\
\text { (ChainD) }\end{array}$ & 10 & $15928 / 7.14$ & 27574253 & 11 & $0.018 \pm 0.004$ & $0.123 \pm 0.006$ & 49 & 79 & $\begin{array}{l}\mathrm{O}_{2} / \mathrm{CO}_{2} \\
\text { transport }\end{array}$ \\
\hline $\begin{array}{l}\text { Deoxy } \\
\text { hemoglobin } \\
\text { (ChainD) }\end{array}$ & 11 & $15928 / 7.14$ & 27574253 & 11 & $0.022 \pm 0.002$ & $0.131 \pm 0.002$ & 49 & 80 & $\begin{array}{l}\mathrm{O}_{2} / \mathrm{CO}_{2} \\
\text { transport }\end{array}$ \\
\hline $\begin{array}{l}\text { Manganese } \\
\text { superoxide } \\
\text { dismutase }\end{array}$ & 12 & $22290 / 6.86$ & 2780819 & 9 & $0.019 \pm 0.006$ & $0.075 \pm 0.001$ & 50 & 57 & $\begin{array}{l}\text { Anti-oxidant } \\
\text { enzyme }\end{array}$ \\
\hline $\begin{array}{l}\text { Alpha } \\
\text { B-Crystallin }\end{array}$ & 13 & $20146 / 6.76$ & 13937813 & 11 & $0.022 \pm 0.001$ & $0.097 \pm 0.014$ & 57 & 56 & Chaperone \\
\hline $\begin{array}{l}\text { Raf Kinase } \\
\text { inhibitor protein }\end{array}$ & 14 & $16068 / 8,81$ & 4261934 & 9 & $0.019 \pm 0.008$ & $0.132 \pm 0.015$ & 45 & 54 & $\begin{array}{l}\text { Signaltrans- } \\
\text { duction }\end{array}$ \\
\hline $\begin{array}{l}\text { Peptidyl- } \\
\text { prolylisomerase A }\end{array}$ & 15 & $18228 / 7,68$ & 13937981 & 13 & $0.02 \pm 0.007$ & $0.109 \pm 0.001$ & 67 & 59 & $\begin{array}{l}\text { Immuno- } \\
\text { philin }\end{array}$ \\
\hline $\begin{array}{l}\text { Peptidyl- } \\
\text { prolylisomerase A }\end{array}$ & 16 & $18228 / 7,68$ & 13937981 & 14 & $0.011 \pm 0.004$ & $0.102 \pm 0.005$ & 67 & 60 & $\begin{array}{l}\text { Immuno- } \\
\text { philin }\end{array}$ \\
\hline Cofilin1 & 17 & $18719 / 8.22$ & 15147369 & 8 & $0.018 \pm 0.008$ & $0.112 \pm 0.012$ & 35 & 45 & Actinturnover \\
\hline HSP27 & 18 & $22427 / 7.83$ & 662841 & 12 & $0.021 \pm 0.001$ & $0.117 \pm 0.003$ & 48 & 51 & Chaperone \\
\hline HSP27 & 19 & $22427 / 7.83$ & 662841 & 16 & $0.014 \pm 0.008$ & $0.097 \pm 0.005$ & 48 & 67 & Chaperone \\
\hline $\begin{array}{l}\text { hnRNPA2/B1 } \\
\text { isoform A2 }\end{array}$ & 20 & $36041 / 8.67$ & 4504447 & 21 & $0.015 \pm 0.007$ & $0.141 \pm 0.021$ & 35 & 53 & $\begin{array}{l}\text { Several } \\
\text { functions }\end{array}$ \\
\hline
\end{tabular}

\footnotetext{
(a) Index in the reference gel (Figure 1).

(b) Expected $\mathrm{Mr}$ and $\mathrm{pI}$ which were calculated on the complete sequences.

(c) Accession number in NCBI.

(d) The individual spot volumes were expressed as a percentage of the total volume in all of the spots present in the gel. N: nontumor tissue; T: tumor tissue.
} 


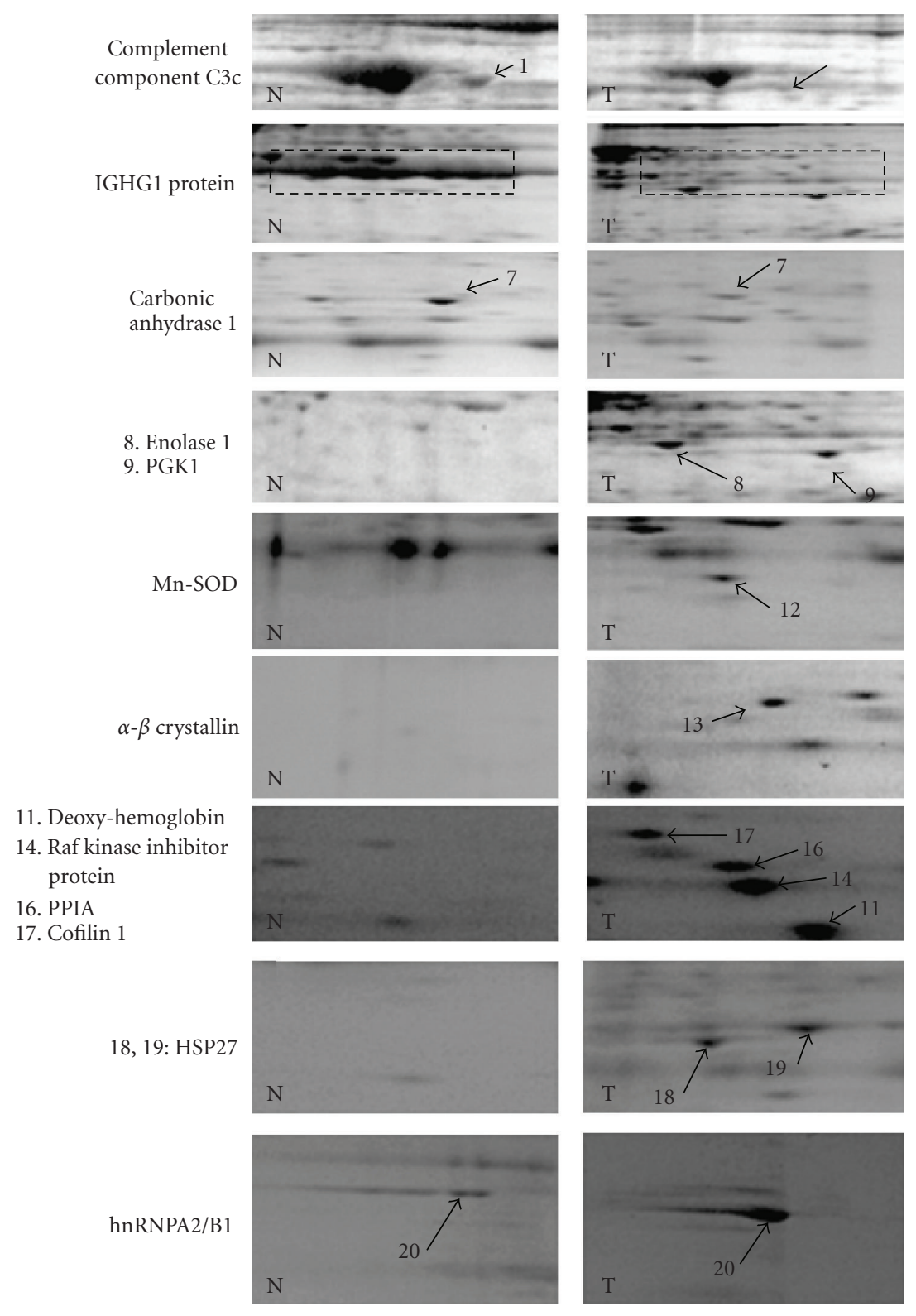

FIGURE 1: 2-DE pattern of proteins from tumor and nontumor samples resolved by NEPHGE 2-DE and listed in Table 1. Proteins dysregulated in tumor tissues $(\mathrm{T})$ as compared to nontumor tissues $(\mathrm{N})$ are highlighted with arrows. The numbers indicated correspond to those given in Table 1. (1)-(7): proteins downregulated in tumor tissues; (8)-(20): proteins upregulated in tumor tissues. (1) complement component C3c; (2)-(6) IGHG1 protein isoforms; (7) carbonic anhydrase 1; (8) enolase 1; (9) phosphoglycerate kinase 1 (PGK1); (10), (11) hemoglobin; (12) MnSOD; (13) $\alpha$-B crystallin; (14) Raf kinase inhibitor protein; (15), (16) peptidylprolylisomerase A (PPIA); (17) cofilin 1; (18), (19) HSP27; (20) hnRNP A2/B1.

the tumor and normal tissues are highlighted with arrows (Figure 1). Among the proteins identified, the levels of 13 proteins were increased in the tumor samples, while 7 proteins were rather observed at higher amounts in the nonneoplastic breast tissues. These alterations were regarded as serious alterations occuring between tumor and nontumor tissues. Altered proteins were subsequently excised and subjected to in-gel tryptic digestion and MALDI-TOF analyses. This procedure allowed the unambiguous identification of the proteins investigated. Figure 2 shows an example of
MALDI-TOF peptide mass fingerprints of the tryptic digests corresponding to alpha B-crystallin. Table 1 lists all of the proteins identified. A wealth of evidence suggests that most of these dysregulated proteins are closely related to neoplastic transformation. These proteins could be classified on the basis of their functions into stress-related, chaperoning proteins, cytoskeletal-related proteins, metabolic enzymes, and other molecules related to immunological responses. Some of these alterations depicted in Figure 1 involve co-upregulations of glycolytic enzymes (enolase1, spot 


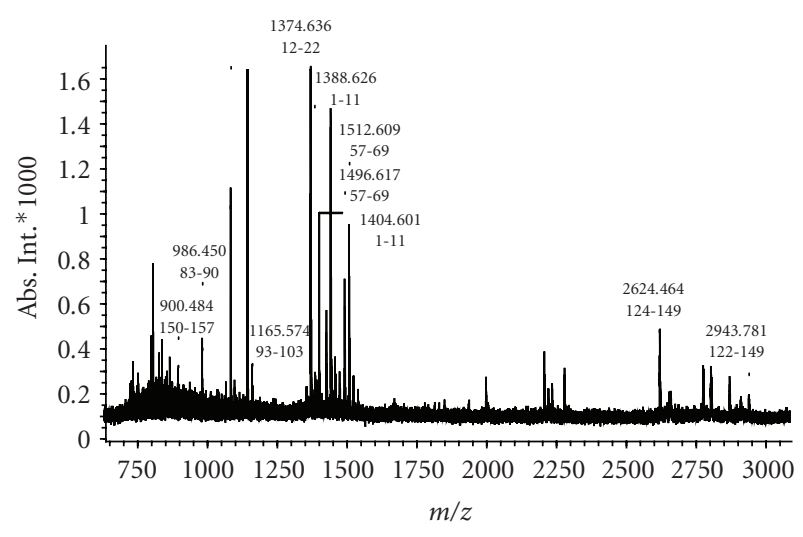

MDIAIHHPWI RRPFFPFHSP SRLFDQFFGE HLLESDLFPT STSLSPFYLR PPSFLRAPSW FDTGLSEMRL EKDRFSVNLD VKHFSPEELK VKVLGDV IEVHGKHEERQDE HGFISREFHR KYRIPADVDP LTITSSLSSD GVLTVN GPRKQVSGPERTIP ITREEKPAVT AAPKK

FIgURE 2: MALDI-TOF peptide mass fingerprints of the tryptic digests corresponding to alpha B-crystallin. The matched peptide sequences are underlined.

8; phosphoglycerate kinase 1, spot 9) in tumor tissues, as well as, proteins involved in antioxidation pathways including peptidylprolyl isomerase A (spots 15, 16), which has been reported to protect cells against oxidative stress and manganese superoxyde dismutase (Mn-SOD, spot 12). Two other newly identified proteins related to immunologic responses present at lower levels in tumor tissues include complement component C3c (spot 1) and IGHG1 (spots 2-6).

More interestingly, the levels of Raf kinase inhibitor protein (spot 14) were found to be overexpressed in cancer tissues indicating a possible special pathological role for this protein in breast carcinogenesis. Other alterations more represented with respect to the IDCA tissues include heat shock proteins (HSP27, spots 18,19 ) and $\alpha$-B-crystallin (spot 13). Subsequent immunohistochemical staining against $\alpha$-Bcrystallin has also been performed (Figure 3). Expression of $\alpha$-B-crystallin was noted in all cases investigated and positivity has been retrieved in 80 to $90 \%$ of tumor cells. The signals detected in tumor cells were strong whereas epithelial cells of the normal tissues express lower levels of this protein.

\section{DISCUSSION}

Proteomics-based studies are increasingly used to examine cancer-related changes in protein expression. Such protein alterations may eventually contribute to increase our understanding of the disease pathogenesis as well as in the development of effective strategies for diagnosis and treatment. The present study aims to investigate protein alterations in IDCAs of the breast using an NEPHGE-2-DE procedure. As shown in this comparative analysis, certain specific proteins were dysregulated in IDCAs compared with their paired normal samples. These altered proteins were subsequently analyzed by mass spectrometry and unambiguously assigned on the basis of MALDI-TOF spectra obtained after trypsin digestion (Table 1). The proteins identified span a wide range of functions and may have a value as diagnostic and prognostic biomarkers for breast cancer. Among the proteins identified, we established that there is a decreased expression of IGG1 and complement component C3c proteins in breasttumor tissues. These alterations related to immunologic responses constitute novel identifications that were not previously reported as potential markers of IDCA breast tumors. As shown in Figure 1, the IGG1 proteins were observed as multiple protein spots with different isoelectric points and similar molecular weights. As displayed in NEPHGE-2-DE gels, these proteins appeared intact as judged by their apparent molecular mass and were closely associated with nonmalignant tissues.

Consistent with our findings, several studies have shown that malignant diseases of various tissue origin are associated with a shift in the IGG subclass distribution. For example, the decrease of IGG1 serum levels reported in colorectal cancer has been considered as an early tissue nonspecific indicator of malignant transformation that could be useful in the primary diagnosis of colorectal tumors [14]. Such alterations were recently reported to occur in colorectal adenocarcinomas and normal colorectal tissues using suppression subtractive hybridization techniques [15]. A highly reduction of the percent of IGG1 in several gynecologic malignant diseases has also been correlated with early carcinoma stages and was found as a reliable marker that discriminates between cancer patients and controls with a specificity ranging between 90 and 100\% [16]. The reduction in IGG1 plasmatic levels has also been reported as a highly sensitive tumor marker for detecting primary and metastatic squamouscell carcinomas of the head and neck [17], and was significantly correlated with early stages of invasive breast cancer [18]. Up to now, such alterations in IGG1 levels were found with neoplastic diseases only and may likely reflect changes in the host's immune system linked to the presence of malignant tumors. Recent data unveiled that malignant tumors of various tissues lead to irregularity of the biosynthesis of IGG1 and IGG2 by affecting their messenger RNA levels in Bcell lymphocytes [19]. It has been hypothesized in this context that cancer cells may affect the synthesis of such IGG subclasses by acting on the T-helper 1/T-helper 2 ratio in the host, and, consequently, affect the level of specific cellderived cytokines implicated in human IGG synthesis [20]. Our observation of underexpression of IGG1 in IDCAs with regard to nontumor tissues may therefore, indicate a similar tumor-associated mechanism by which cancer cells affect IGG1 synthesis. Further investigations are needed however, to elucidate how malignant breast tissues may interfere with the T-cell mediated regulation of IGG suclasses. Interestingly, downregualtion of IGG1 levels and concomitant downregulation of complement component $\mathrm{C} 3 \mathrm{c}$ were observed in our results. To our knowledge, no studies have yet reported the decreased expression of this protein in IDCAs of the breast. The differential tissue expression of this complement protein provides evidence for the involvement of anti-inflammatory processes in IDCA tissues and may indicate a selective adaptation by breast tumors to escape elimination by antitumor immune responses. Until recently, several studies with normal and malignant tissues have disclosed the presence of 


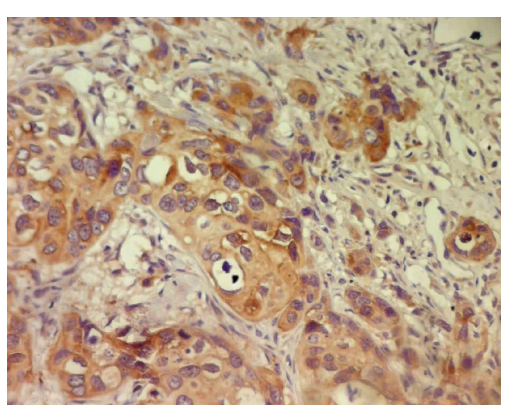

(a)

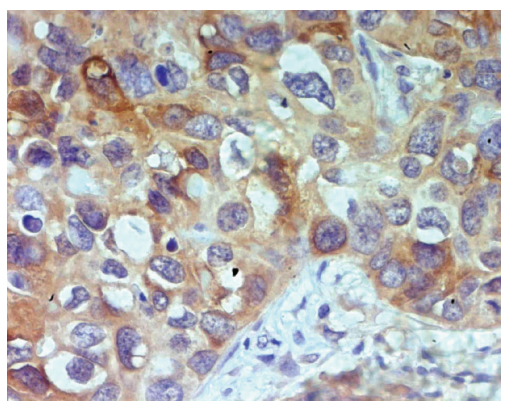

(c)

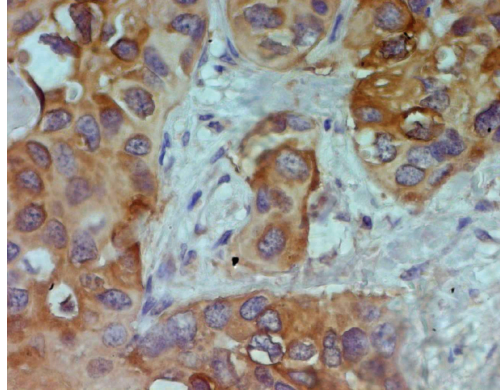

(b)

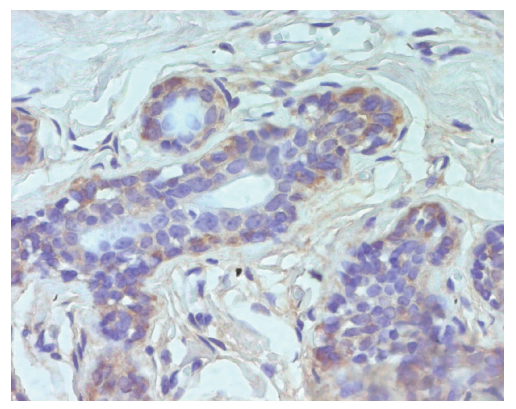

(d)

Figure 3: Overexpression of $\alpha$-B crystallin in infiltrating ductal carcinoma tissues of the breast. Formalin-fixed, paraffin-embedded sections were immunostained with rabbit polyclonal antibody against $\alpha$-B crystallin. Tissues were stained with hematoxylin and viewed by light microscopy. A strong staining (brown) in tumor cells (T) has been observed, whereas $\alpha$-B crystallin was expressed at lower levels in normal epithelial cells. (a) $\alpha$-B crystallin expression in IDCA tissues (200x magnification), (b)-(c) $\alpha$-B crystallin expression in IDCA (400x magnification), (d) $\alpha$-B crystallin expression in nontumor tissues (400x magnification).

several immune escape strategies by which cancer cells protect themselves from the lytic action mediated by complement. Several evasion strategies to complement attack have been reported in malignant cells and include complement protective proteins (CD46, CD55, CD59), membrane proteases reported to confer complement resistance by removing cell-bound complement components such as C3 and tumor secreted complement inhibitors [21]. Such inhibitory mechanisms, often upregulated in tumors, are thought to increase resistance to complement in malignant tissues through inhibition of serum complement activation upon cancer cells. A previous study using a rat model of human breast cancer unveiled that inhibitors of complement activation may facilitate tumor growth and enhance tumorigenicity of breast-cancer cells by inhibiting C3 deposition [22]. The present downregulation of complement C3 component C3c in IDCAs may, therefore, indicate the involvement in breast tumors of similar complement inhibitory mechanisms.

The Raf kinase inhibitor protein (RKIP) known also as phosphatidylethanolamine binding protein-1 (PEBP-1) is another basic protein that has been described as being a component of the important feedback inhibition in G-protein coupled signal transduction [23]. It is also involved in the regulation of the NF-kappa B pathway and is associated with resistance to TNF- $\alpha$ by inhibiting activation of the Raf 1/MEK/extracellular signal regulated kinase pathway, JNK, and phosphatidylethanolamine (PE) externalization, which is an early symptom of apoptotic cell death resulting in the total loss of asymmetric distribution of aminophospholipids in the plasma membrane bilayer $[24,25]$. It has also been reported that overexpressing a new member of the PEBP family (PEBP-4) correlates with both a decreased TNF- $\alpha$ induced PE externalization and resistance to TNF- $\alpha$-induced apoptosis [26]. Interestingly, recent data revealed that silencing of PEBP-4 expression in MCF-7 breast-cancer cells promotes TNF- $\alpha$-induced apoptosis, as well as TNF- $\alpha$-induced ERK and JNK activation making this PE binding protein as a promising target for the treatment of breast cancer [27]. Overall, the present findings in IDCAs of the breast might reflect the previously reported results for the relation between PE-binding proteins and TNF-related apoptosis pathway. The present increase in RKIP may confer breast-cancer cells to an advantage for survival and proliferation.

From our results, the high abundance of hemoglobin in breast tumors could not be considered as a reliable parameter for distinguishing between tumor and nontumor tissues. Indeed, the relationship between tissue hemoglobin levels and breast tumors appears indirect and indicates rather an enhanced blood supply to the tumor. Since tumor angiogenesis is a crucial arbiter of breast-cancer growth/metastasis, this higher level of hemoglobin is consistent with the higher vascular density of growing tumors compared with normal tissues.

Besides these alterations, the concomitant upregulation of two other stress-related proteins (peptidylprolylisomerase A, MnSOD) was observed in IDCAs. The 
peptidylprolylisomerase A also called cyclophilinA (CypA) is described as being involved in protein folding and catalyzes the cis/trans-isomerization of peptide bonds preceding a proline residue. It is secreted by cells in response to both inflammatory stimulation and oxidative stress [28]. Our observation on the expression of CypA is consistent with the published results from studies on other cancers. Overexpression of CypA has been reported in colorectal carcinomas in comparison to normal mucosa and is involved in lung-tumor growth by affecting proliferation and apoptosis [29]. A recent study has shown that both CypA and its receptor CD147 are upregulated in human pancreatic adenocarcinomas compared to normal pancreatic ductal epithelium [30]. These authors pointed that CypA is a promoter of pancreatic tumor growth and is involved in chemotaxis and cell signalling cascades. The present finding reveals a similar correlation, implying that breast carcinomas may share a similar mechanism of cell proliferation mediated by CypA. The MnSOD is a mitochondrial enzyme that has been reported to protect cells against oxidative stress by increasing the dismutation rate of superoxide anion $\left(\mathrm{O}_{2}^{-}\right)$to hydrogen peroxide $\left(\mathrm{H}_{2} \mathrm{O}_{2}\right)$ which is then converted into water by catalase and glutathione peroxidase. The role of this antioxidant enzyme in carcinogenesis is still however controversial and unclear. In fact although, it has been reported to suppress apoptosis and protect cells against several insults, under some circumstances, the MnSOD may prevent cell proliferation [31]. Although further studies are needed, the present elevation of MnSOD may indicate that the antioxidant defense system has been stimulated in invasive carcinomas of the breast, highlighting the ability of tumor cells to prevent damage due to reactive oxygen species.

Interestingly, the co-upregulation of two glycolytic enzymes, enolase 1 and phosphoglycerate kinase 1 (PGK-1) also occurred in IDCA tissues. These enzymes are key components of the glycolytic pathway that have shown a prior relationship to cancer. Indeed, our observation of increased expression of enolase 1 and PGK-1 is supported in various tumor tissues and may relate to the increased requirement of both energy and protein synthesis/degradation pathways during carcinogenesis [32]. This increased glycolytic metabolism is also thought to regulate hypoxia-inducible gene expression in solid tumor tissues and participates in angiogenesis [33].

The protein cofilin-1 also was identified as differentially expressed between tumor and normal tissues. This protein is recruited at the leading edge of cells where its activation is essential for polarized migration. Cofilin-1 is directly implicated in severing actin cytoskeleton filaments and regulates the polymerization/depolymerization of actin during cell migration [34]. It has been recently demonstrated that cofilin expression is required for tumor cell invasion since inhibition of cofilin activity in carcinoma cells inhibits cell motility whereas increased expression correlates with enhanced cell migration [35]. More recently, Wang et al. [34] have demonstrated that overexpression of cofilin-1 is necessary for the activation of the cofilin pathway resulting in cell motility, invasion and metastasis. This protein has also been associated with melanoma cell invasion and migration via its interaction with the $\alpha \mathrm{v} \beta 3$ integrin [36]. Overall, the current findings support the recently identified role for cofilin activity and highlight its involvement in invasive lesions of the breast as a determinant factor required for cell migration and invasion.

The molecular chaperone HSP27 and alpha B-crystallin, which is a small heat shock protein (HSP) are two other dysregulated proteins in tumor tissues. In a previous investigation, we have reported that three other molecular chaperones (GRP78, calreticulin, protein disulfide isomerase) are differentially expressed in breast tumors [9]. The concomitant upregulation of these HSPs together with alpha B-crystallin and HSP27 is not surprising since chaperones are thought to work cooperatively to fulfil their functions [37]. Due to the capacity of HSPs to prevent stress-accumulated, unfolded, and nascent protein aggregation, their expression has proven to have important pathological implications such as cell proliferation and disease prognosis [4]. The HSP27 is a molecular chaperone whose rate of synthesis increases many folds in response to environmental stress and during malignant transformation [38]. As shown in Figure 1, this protein exists as two distinct isoforms that were confirmed by mass spectrometry as HSP27 (Table 1). Although no evidence of posttranslational alterations was pointed out, these isoforms as reported in renal cell carcinomas might reflect phosphorylation or other posttranslational modifications [39]. In the last years, the role of alpha B-crystallin in cancer pathology has been widely discussed with regard to its potential oncogenic role. Previous studies unveiled that this small HSP may constitute a good target for modulating cell death pathways [40]. Its expression has been shown to inhibit both the mitochondrial and the receptor death activation pathways of caspase 3 [41] and correlates with TRAIL resistance in a panel of cancer cell lines [42]. This protein may also be an interesting molecular target for exploring the evolution and the origin of breast tumors since higher alpha B-crystallin levels were reported in ductal carcinoma in situ, which is an earliest form of detectable breast cancer [5]. The data reported herein appear to confirm this for invasive carcinomas as well. Although further studies are needed to answer how this oncoprotein contributes to breast cancer, the data reported herein highlight the importance of this molecular chaperone in invasive carcinomas as a biomarker that may play a distinctive role in the process of carcinogenesis.

\section{CONCLUSION}

In summary, our data have shown the value of using an NEPHGE 2-DE based proteomic approach in identifying potential molecular alterations and targets for breastcancer therapeutics and diagnostics. We have identified a number of tumor-associated proteins including chaperones, energy-producing enzymes, stress-related proteins, proteins involved in apoptosis and cell motility, as well as alterations highlighting changes in the host's immune system linked to the presence of malignant tissues. These protein variations indicate that multiple cellular pathways are involved in the process of breast carcinogenesis. Such alterations may help 
to better understand the pathology of this disease and may have potential clinical applications as cancer biomarkers.

\section{ACKNOWLEDGMENTS}

Both authors contributed equally to the study. This work was supported by le Ministère de l'Enseignement Supérieur et de la Recherche Scientifique, le Ministère de la Santé Publique de la République Tunisienne, and by the Centre National de Recherche Scientifique (Strasbourg, France) and the DGRST-CNRS funding program.

\section{REFERENCES}

[1] A. Jemal, A. Thomas, T. Murray, and M. Thun, "Cancer statistics," CA: A Cancer Journal for Clinicians, vol. 52, no. 1, pp. 23-47, 2002.

[2] D. M. Parkin, J. Ferlay, M. Hamdi Cherif, et al., Cancer in Africa: Epidemiology and Prevention, IARC Scientific Publications, IARC Press, Lyon, France, 2003.

[3] H. Hondermarck, "Breast cancer: when proteomics challenges biological complexity," Molecular \& Cellular Proteomics, vol. 2, pp. 281-291, 2003.

[4] Q.-Y. He, J. Chen, H.-F. Kung, A. P.-W. Yuen, and J.-F. Chiu, "Identification of tumor-associated proteins in oral tongue squamous cell carcinoma by proteomics," Proteomics, vol. 4, no. 1, pp. 271-278, 2004.

[5] J. D. Wulfkuhle, D. C. Sgroi, H. Krutzsch, et al., "Proteomics of human breast ductal carcinoma in situ," Cancer Research, vol. 62, no. 22, pp. 6740-6749, 2002.

[6] A. Görg, W. Weiss, and M. J. Dunn, "Current two-dimensional electrophoresis technology for proteomics," Proteomics, vol. 4, no. 12, pp. 3665-3685, 2004.

[7] B. R. Herbert, C. Sanchez, and L. Bin, "Two dimensional electrophoresis: the state of the art and future directions," in Proteome Research: New Frontiers in Functional Genomics, M. R. Wilkins, K. I. Williams, R. D. Appel, and D. F. Hochstrasser, Eds., pp. 13-33, Springer, New York, NY, USA, 1997.

[8] P. Z. O'Farrell, H. M. Goodman, and P. H. O’Farrell, “High resolution two-dimensional electrophoresis of basic as well as acidic proteins," Cell, vol. 12, no. 4, pp. 1133-1142, 1977.

[9] K. Chahed, M. Kabbage, L. Ehret-Sabatier, et al., "Expression of fibrinogen E-fragment and fibrin E-fragment is inhibited in the human infiltrating ductal carcinoma of the breast: the two-dimensional electrophoresis and MALDI-TOF-mass spectrometry analyses," International Journal of Oncology, vol. 27, no. 5, pp. 1425-1431, 2005.

[10] L. H. Sobin and I. D. Fleming, "TNM classification of malignant tumors,fifth edition. Union Internationale Contre le Cancer and the American Joint Committee on Cancer," Cancer, vol. 80, no. 9, pp. 1803-1804, 1997.

[11] C. W. Elston and I. O. Ellis, "Pathological prognostic factors in breast cancer. I. The value of histological grade in breast cancer: experience from a large study with long-term followup," Histopathology, vol. 19, no. 5, pp. 403-410, 1991.

[12] L. S. Ramagli and L. U. Rodriguez, "Quantification of microgram amounts of proteins in two-dimensional polyacrylamide gel electrophoresis sample buffer," Electrophoresis, vol. 6, no. 11, pp. 559-563, 1985.
[13] V. Neuhoff, R. Stamm, and H. Eibl, "Clear background and highly sensitive protein staining with Coomassie Blue dyes in polyacrylamide gels: a systematic analysis," Electrophoresis, vol. 6, no. 9, pp. 427-448, 1985.

[14] E. Schauenstein, H. Rabl, W. Steinschifter, C. Hirschmann, W. Estelberger, and K. Schauenstein, "Selective decrease of serum immunoglobulin G1 as a marker of malignant transformation in colorectal tissue," Cancer, vol. 79, no. 8, pp. 1482-1486, 1997.

[15] Y. Chen, Y.-Z. Zhang, Z.-G. Zhou, G. Wang, and Z.-N. Yi, "Identification of differently expressed genes in human colorectal adenocarcinoma," World Journal of Gastroenterology, vol. 12, no. 7, pp. 1025-1032, 2006.

[16] E. Schauenstein, M. Lahousen, M. Weblacher, W. Steinschifter, W. Estelberger, and K. Schauenstein, "Selective decrease in serum immunoglobulin G1: a tissue nonspecific tumor marker detecting early stages of gynecologic malignant disease with high efficiency," Cancer, vol. 78, no. 3, pp. 511516, 1996.

[17] W. Anderhuber, W. Steinschifter, A. Gotschuli, E. Schauenstein, and K. Schauenstein, "Quantitative changes in the immunoglobulin $\mathrm{G}$ subclass system-a reliable tumor marker in squamous epithelial carcinoma in the area of the head-neck," Laryngorhinootologie, vol. 77, no. 10, pp. 564-568, 1998.

[18] L. Kronberger, W. Steinschifter, M. Weblacher, et al., "Selective decrease of serum immunoglobulin G1 as marker for early stages of invasive breast cancer," Breast Cancer Research and Treatment, vol. 64, no. 2, pp. 193-199, 2000.

[19] P. Felsner, W. Steinschifter, M. Fischer, et al., "The tumorassociated shift in immunoglobulin G1/G2 is expressed at the messenger RNA level of peripheral blood B lymphocytes in patients with gynecologic malignancies," Cancer, vol. 88, no. 2, pp. 461-467, 2000.

[20] Y. Kawano, T. Noma, and J. Yata, "Regulation of human IgG subclass production by cytokines: IFN- $\gamma$ and IL- 6 act antagonistically in the induction of human IgG1 but additively in the induction of IgG2," Journal of Immunology, vol. 153, no. 11, pp. 4948-4958, 1994.

[21] K. Jurianz, S. Ziegler, N. Donin, Y. Reiter, Z. Fishelson, and M. Kirschfink, "K562 erythroleukemic cells are equipped with multiple mechanisms of resistance to lysis by complement," International Journal of Cancer, vol. 93, no. 6, pp. 848-854, 2001.

[22] T. A. Caragine, N. Okada, A. B. Frey, and S. Tomlinson, "A tumor-expressed inhibitor of the early but not late complement lytic pathway enhances tumor growth in a rat model of human breast cancer," Cancer Research, vol. 62, no. 4, pp. 1110-1115, 2002.

[23] K. Lorenz, M. J. Lohse, and U. Quitterer, "Protein kinase C switches the Raf kinase inhibitor from Raf-1 to GRK-2," $\mathrm{Na}$ ture, vol. 426, no. 6966, pp. 574-579, 2003.

[24] K. Yeung, P. Janosch, B. McFerran, et al., "Mechanism of suppression of the Raf/MEK/extracellular signal-regulated kinase pathway by the Raf kinase inhibitor protein," Molecular and Cellular Biology, vol. 20, no. 9, pp. 3079-3085, 2000.

[25] K. Emoto, N. Toyama-Sorimachi, H. Karasuyama, K. Inoue, and M. Umeda, "Exposure of phosphatidylethanolamine on the surface of apoptotic cells," Experimental Cell Research, vol. 232, no. 2, pp. 430-434, 1997.

[26] X. Wang, N. Li, B. Liu, et al., "A novel human phosphatidylethanolamine-binding protein resists tumor necrosis factor $\alpha$-induced apoptosis by inhibiting mitogen-activated protein kinase pathway activation and phosphatidylethanolamine externalization," Journal of Biological Chemistry, vol. 279, no. 44, pp. 45855-45864, 2004. 
[27] X. Wang, N. Li, H. Li, et al., "Silencing of human phosphatidylethanolamine-binding protein 4 sensitizes breast cancer cells to tumor necrosis factor- $\alpha$-induced apoptosis and cell growth arrest," Clinical Cancer Research, vol. 11, no. 20, pp. 7545-7553, 2005.

[28] B. Sherry, N. Yarlett, A. Strupp, and A. Cerami, "Identification of cyclophilin as a proinflammatory secretory product of lipopolysaccharide-activated macrophages," Proceedings of the National Academy of Sciences of the United States of America, vol. 89, no. 8, pp. 3511-3515, 1992.

[29] C. Melle, D. Osterloh, G. Ernst, B. Schimmel, A. Bleul, and F. von Eggeling, "Identification of proteins from colorectal cancer tissue by two-dimensional gel electrophoresis and SELDI mass spectrometry," International Journal of Molecular Medicine, vol. 16, no. 1, pp. 11-17, 2005.

[30] M. Li, Q. Zhai, U. Bharadwaj, et al., "Cyclophilin A is overexpressed in human pancreatic cancer cells and stimulates cell proliferation through CD147," Cancer, vol. 106, no. 10, pp. 2284-2294, 2006.

[31] M. D. Wheeler, O. M. Smutney, and R. J. Samulski, "Secretion of extracellular superoxide dismutase from muscle transduced with recombinant adenovirus inhibits the growth of B16 melanomas in mice," Molecular Cancer Research, vol. 1, no. 12, pp. 871-881, 2003.

[32] J. Chen, Q.-Y. He, A. P.-W. Yuen, and J.-F. Chiu, "Proteomics of buccal squamous cell carcinoma: the involvement of multiple pathways in tumorigenesis," Proteomics, vol. 4, no. 8, pp. 2465-2475, 2004.

[33] O. Trabold, S. Wagner, C. Wicke, et al., "Lactate and oxygen constitute a fundamental regulatory mechanism in wound healing," Wound Repair and Regeneration, vol. 11, no. 6, pp. 504-509, 2003.

[34] W. Wang, G. Mouneimne, M. Sidani, et al., "The activity status of cofilin is directly related to invasion, intravasation, and metastasis of mammary tumors," Journal of Cell Biology, vol. 173, no. 3, pp. 395-404, 2006.

[35] C. T. Yap, T. I. Simpson, T. Pratt, D. J. Price, and S. K. Maciver, "The motility of glioblastoma tumour cells is modulated by intracellular cofilin expression in a concentration-dependent manner," Cell Motility and the Cytoskeleton, vol. 60, no. 3, pp. 153-165, 2005.

[36] D. Dang, J. R. Bamburg, and D. M. Ramos, " $\alpha \mathrm{v} \beta 3$ integrin and cofilin modulate K1735 melanoma cell invasion,” Experimental Cell Research, vol. 312, no. 4, pp. 468-477, 2006.

[37] J. G. Kiang and G. C. Tsokos, "Heat shock protein $70 \mathrm{kDa}$ : molecular biology, biochemistry, and physiology," Pharmacology \& Therapeutics, vol. 80, no. 2, pp. 183-201, 1998.

[38] I. Korneeva, A. M. Bongiovanni, M. Girotra, T. A. Caputo, and S. S. Witkin, "IgA antibodies to the $27 \mathrm{kDa}$ heat-shock protein in the genital tracts of women with gynecologic cancers," International Journal of Cancer, vol. 87, no. 6, pp. 824-828, 2000.

[39] C. Sarto, C. Valsecchi, F. Magni, et al., "Expression of heat shock protein 27 in human renal cell carcinoma," Proteomics, vol. 4, no. 8, pp. 2252-2260, 2004.

[40] A. Parcellier, E. Schmitt, M. Brunet, A. Hammann, E. Solary, and C. Garrido, "Small heat shock proteins HSP27 and $\alpha \mathrm{B}$ crystallin: cytoprotective and oncogenic functions," Antioxidants \& Redox Signaling, vol. 7, no. 3-4, pp. 404-413, 2005.

[41] M. C. Kamradt, F. Chen, and V. L. Cryns, "The small heat shock protein $\alpha \mathrm{B}$-crystallin negatively regulates cytochrome $c$ and caspase-8-dependent activation of caspase- 3 by inhibiting its autoproteolytic maturation," Journal of Biological Chemistry, vol. 276, no. 19, pp. 16059-16063, 2001.
[42] M. C. Kamradt, M. Lu, M. E. Werner, et al., "The small heat shock protein $\alpha \mathrm{B}$-crystallin is a novel inhibitor of TRAILinduced apoptosis that suppresses the activation of caspase-3," Journal of Biological Chemistry, vol. 280, no. 12, pp. 1105911066, 2005. 


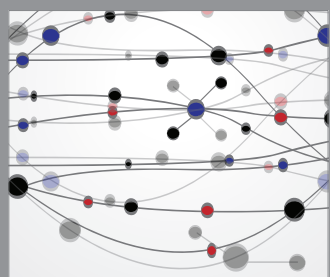

The Scientific World Journal
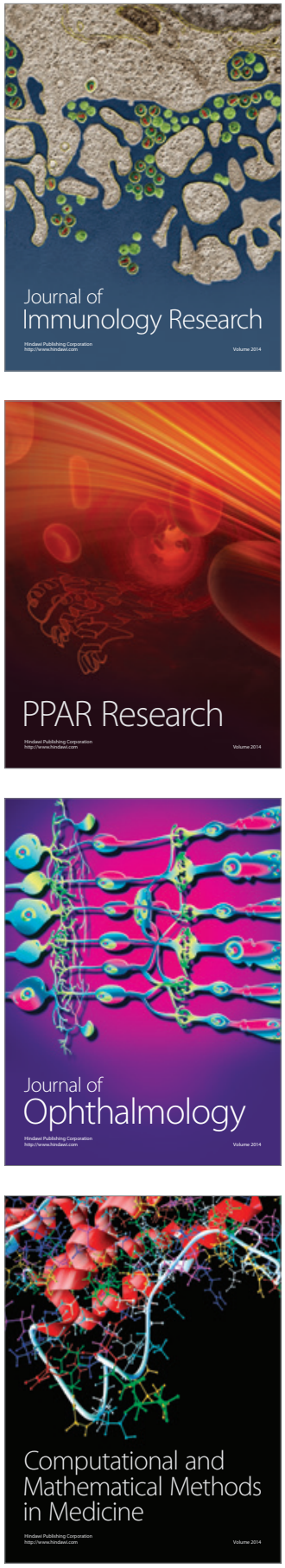

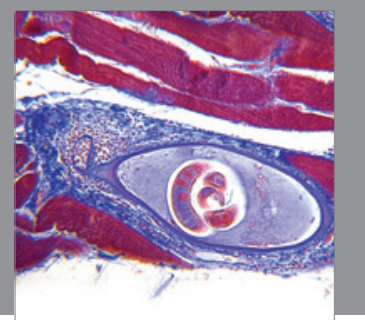

Gastroenterology

Research and Practice
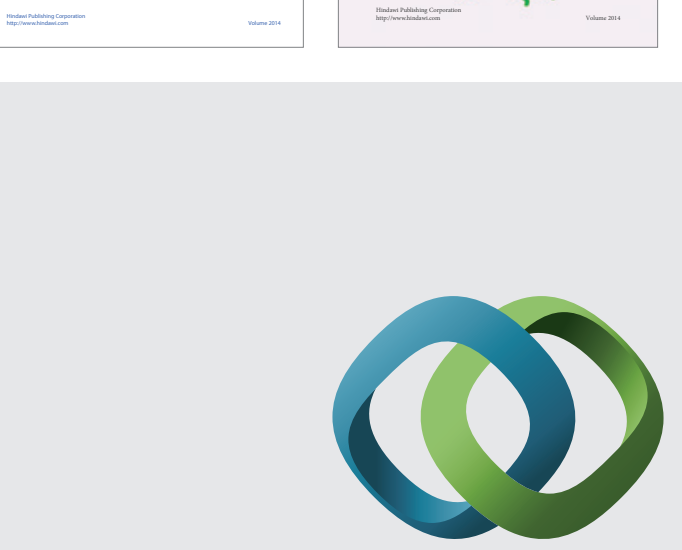

\section{Hindawi}

Submit your manuscripts at

http://www.hindawi.com
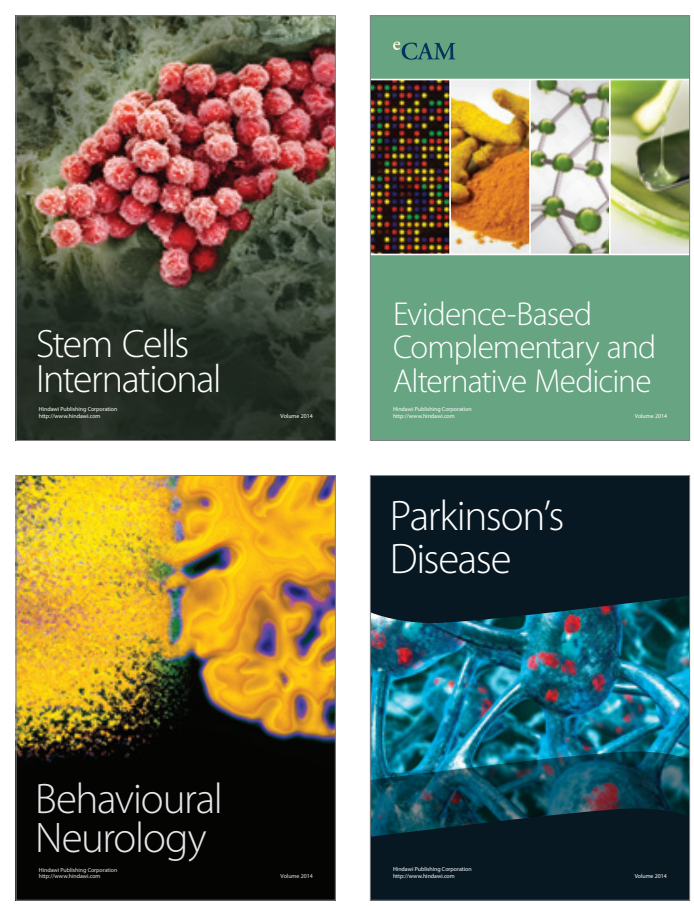

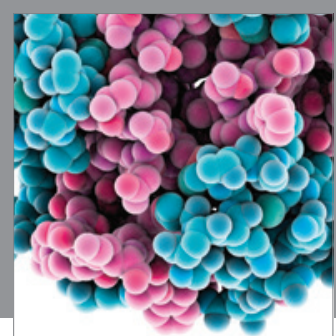

Journal of
Diabetes Research

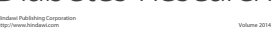

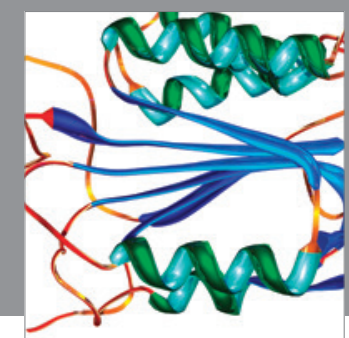

Disease Markers
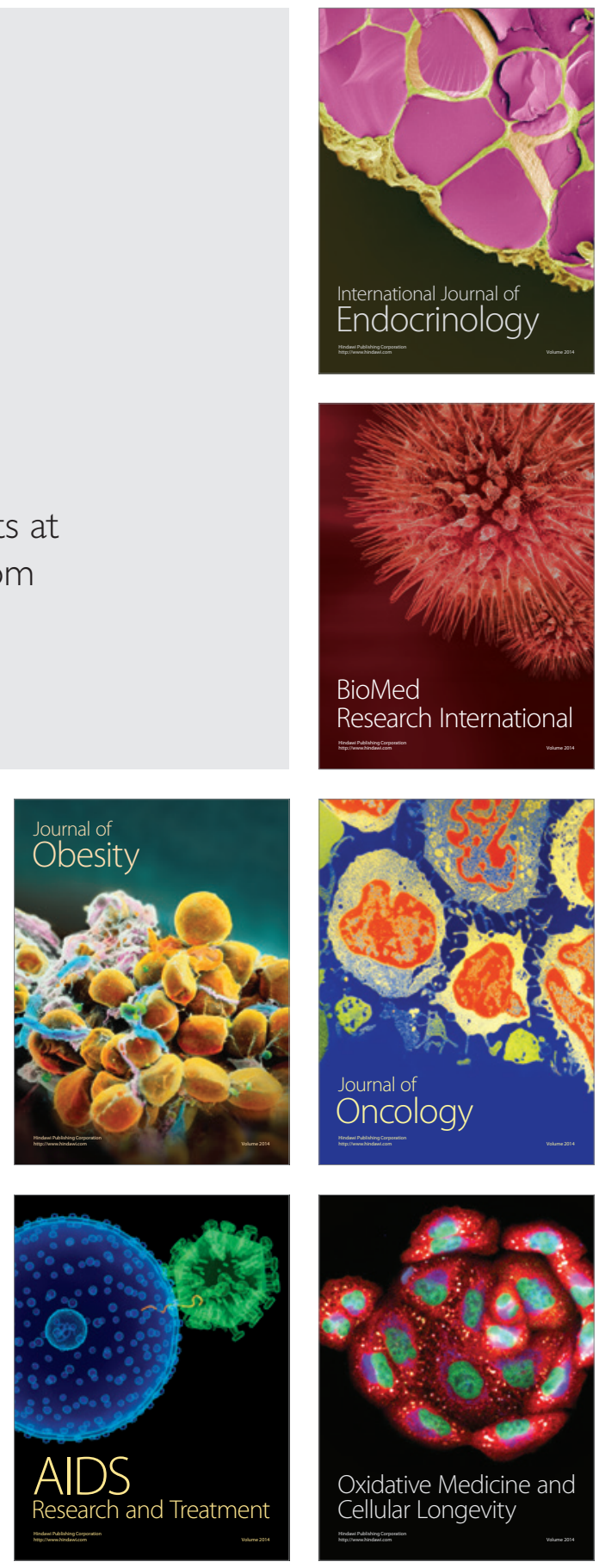